\title{
Comparison of selected muscular activity of trunk and lower extremities in young women's walking on supinated, pronated and normal foot
}

\author{
Hamideh Khodaveisi ${ }^{a, *}$, Haydar Sadeghi ${ }^{a}$, Raghad Memar ${ }^{a}$, Mehrdad Anbarian $^{b}$ \\ a Department of Sport Biomechanics, School of Physical Education and Sport Sciences, Kharazmi University, Tehran, Iran \\ ${ }^{b}$ Department of Sport Biomechanics, School of Physical Education and Sport Sciences, Bu-Ali Sina University, Hamadan, Iran
}

Received 26 May 2015; accepted 27 October 2015

Available online 7 January 2016

\section{KEYWORDS}

Lower limb muscles;

Gait;

Normal foot;

Pronated foot;

Supinated foot

\begin{abstract}
Changes in anatomical structure of the foot reduce the foot ability for normal performance. This study aimed to compare selected muscles of trunk and lower extremities during walking in individuals with different foot types. Forty-five female students were categorized into three groups depending on their foot structures namely, pronated, supinated and normal feet. Foot types defined by foot posture index and X-ray under the specialist physician. Electromyography activities were recorded from muscles of tibialis anterior, peroneus longus, medial gastrocnemius, biceps femoris, gluteus medius, external oblique and erector spinae in three groups while walking in determined path with self-selected gait speed. Each effort simultaneous with electromyography registration was recorded with camera. One-way ANOVA test was used to compare the groups at significance level of 0.05 . The activity of muscle of tibialis anterior and medial gastrocnemius was greater in pronated foot group than that in supinated and normal groups during heel contact phase of gait $(p=0.001)$. Supinated foot group exhibited a greater peroneus longus activation than the other groups $(p=0.001)$. No significant differences were observed for remaining four muscles $(p>0.05)$. During midstance phase, peroneus longus, supinated foot group exhibited a greater activity compared to other groups while pronated foot group exhibited a greater muscle activity for gluteus medius than others $(p=0.001)$. There was a significant difference between normal and pronated foot groups for external oblique $(p=0.001)$. Regarding the findings of this study, the muscular performance changes in pronated and supinated foot groups are more noticeable than that in normal foot type.

(c) 2015 Published by Elsevier España, S.L.U. on behalf of Consell Català de l'Esport. Generalitat de Catalunya.
\end{abstract}

\footnotetext{
* Corresponding author.

E-mail address: khodaveisi_hamideh@yahoo.com (H. Khodaveisi).
} 
PALABRAS CLAVE

Músculos de las extremidades

inferiores;

Marcha;

Pie neutro;

Pie pronador;

Pie supinador
Comparación de la actividad muscular seleccionada del tronco y las extremidades inferiores en la forma de caminar de las mujeres jóvenes con pies supinadores, pronadores y neutros

Resumen Los cambios en la estructura anatómica del pie reducen su capacidad de rendimiento normal. Este estudio trató de comparar los músculos seleccionados del tronco y las extremidades inferiores al caminar, en personas con diferentes tipos de pie. Se clasificó a 45 estudiantes femeninas en tres grupos, dependiendo de la estructura de sus pies, es decir, pronadora, supinadora y neutra. El médico especialista definió los tipos de pie mediante el índice postural del pie y rayos $X$. Se registraron las actividades electromiográficas de los músculos tibial anterior, peroneo lateral largo, gemelo interno, bíceps femoral, glúteo medio, externo oblicuo y erector de la columna en los tres grupos, al realizar un recorrido determinado, con una velocidad de marcha auto-seleccionada. Se grabó con una cámara cada esfuerzo simultáneo al registro electromiográfico. Se utilizó el test ANOVA con un factor para comparar los grupos, con un nivel de significación de 0,05. La actividad de los músculos tibial anterior y gemelo interno fue superior en el grupo de pie pronador que en los grupos de pie supinador y neutro, durante la fase de contacto del talón de la marcha $(p=0,001)$. El grupo de pie supinador reflejó una activación superior del músculo peroneo lateral largo que el resto de los grupos $(p=0,001)$. No se observaron diferencias significativas en los cuatro músculos restantes $(p>0,05)$. Durante la fase de media distancia, para el peroneo lateral largo, el grupo de pie supinador reflejó una mayor actividad en comparación a los demás grupos, mientras que el grupo de pie pronador reflejó una mayor actividad muscular para el glúteo medio que los demás grupos $(p=0,001)$. Se produjo una diferencia significativa entre los grupos de pie pronador y pie neutro para el externo oblicuo $(p=0,001)$. Con arreglo a los hallazgos de este estudio, los cambios en el desempeño muscular en los grupos de pies pronadores y supinadores son más notorios que en el grupo de pie neutro.

(C) 2015 Publicado por Elsevier España, S.L.U. en nombre de Consell Català de l'Esport. Generalitat de Catalunya.

\section{Introduction}

In walking foot bears the performance of absorbing contact forces with the ground, balancing, and adaptation to ground surfaces and transmission of forces efficiently, which are obtained through mutual activities of foot joints. ${ }^{1}$

The important movements occur at the talocrural, subtalar, talonavicular, calcaneocuboid and navicular-cuboid joints during walking. ${ }^{2}$ The recent studies point out individual differences and high complexity of tarsal movements which can be summarized into pronation and supination movements. Pronation occurs in the midstance which helps to increases the available motion of the forefoot, shock absorption and adaptation to ground. Toward the end of stance, foot supination increases and leads to decrease available motion of the forefoot resulting in stability to the front. ${ }^{1}$

Unnatural biomechanics of foot reduces the foot ability to do normal performance. ${ }^{3}$ Pronated foot is on the most common reasons of people's referring to orthopedics and clinics as seen in a wide range of deformities such as reduction of medial longitudinal arch height, heel external rotation and anterior foot abduction. ${ }^{4}$ It is generally believed that pronated foot acts as a facilitator in bringing about overtraining damages and pathologic conditions such as plantar fasciitis, Achilles tendon shortening, stress fracture, shin splint and pain in heel, knee and back. ${ }^{5}$
Heel internal rotation concomitant with medial longitudinal arch height is called supinated foot contributing to a wide range of lower extremity deformities such as forefoot adduction, finger forking, genu varum and other symptoms. ${ }^{6}$ it was structurally determined that for people with this deformity. During walking, time and area of contact with ground become less and they have weak shock absorption due to locking of midtarsal joints. ${ }^{7}$ Foot pronation and supination are abnormalities when contribute to structural and performance deficiencies in standing and walking with changes in lower-extremity, lumbar-pelvic area and lower extremity muscles. ${ }^{8}$ In contrast to disturbance in proximal muscle performance, it is effective on distal muscle performance. ${ }^{9}$ Over pronation and over supination of subtalar joint can change the position of hip, pelvis and trunk and upper extremities. ${ }^{8}$ Over pronation is concomitant with tibia internal rotation, femur ${ }^{10}$ and knee valgus ${ }^{11,12}$ and pelvis anterior tilt. ${ }^{13,14}$ Supinated foot is accompanied by external rotation of the tibia ${ }^{15}$ consequently, the femur rotates in the same direction as the tibia, and the femoral neck angle influences knee angle and position. Thus, supinated foot may contribute to lower limbs dysfunction. It is reasonable to assume that close chain activity in lower limb may alter the mechanical alignment and dynamic function in proximal joint. Hansen ${ }^{15}$ noted that an overpowering posterior tibialis muscle is an apparent feature in subjects with supinated foot. This muscle inverts and internally rotates 
foot in relation to the leg, and these actions are facilitated by weakness or full paralysis of the peroneus brevis. When this occurs, the posterior tibialis becomes an external rotator of the tibia in relation to the foot.

Review of kinematic studies comparing individuals' movement performance on normal and pronated foot in walking. Shows that in individuals with pronated foot, due to the situation of heel external rotation and internal longitudinal arch collapse, subtalar joint stays in pronation position in the ending of stance, therefore, foot bone stability reduces and foot confronts lack of force to progress in toe-off. ${ }^{16,17}$ On the other hand, elongation of heel eversion ${ }^{16,17}$ and increase of internal rotation of tibias in loading response ${ }^{18}$ can disturb the main performance of muscular-skeletal structure of foot as a force absorbent.

Foot deformities create some changes in the movement of lower extremities and in some cases increase the risk of injury. The relationship between foot deformities and increasing the risk of lower extremities injury can originate from abnormal activity of muscles. For example, it is reported that individuals with flat foot exhibited increased or decreased activity of the lower limbs as a neuromuscular reflect compensation to reduce overload resulting from foot deformity during walking. 4,17

In electromyography, Murley et al. ${ }^{4}$ showed that pronated group act higher percentage of maximal EMG amplitude for tibialis anterior in contact and for tibialis posterior in midstance than normal group. In addition, for peroneus longus, it was specified that this group has lower activity of EMG in stance. While in some studies there is no report of such difference. ${ }^{19}$ During walking, the trunk muscles have been seen to play various roles related control of motion between the trunk and pelvis, ${ }^{20}$ which are of great importance in decreasing the vertical movement of the body and shock absorption during walking. ${ }^{21}$ As superficial muscles such as erector spinae are linked with the muscles acting on the foot and hip. ${ }^{22,23}$ And could be influenced by changes of myofascial tension, ${ }^{24}$ deformity in their activation pattern would be expected to affect upper extremity muscles as a result of imbalance. ${ }^{25}$

Therefore, it is necessary to do researches about the physiological response and selected muscle activity of trunk and lower extremities to different postures of foot in walking which result in elucidation of incidence mechanism and prevention from damages.

Regarding the anatomical structure and position of foot and reduction of foot performance in abnormal structure and limitations of previous researches in investigating muscles, it is of great importance to understand the muscle activity during walking on supinated and pronated foot compared with normal foot. Therefore this study aims to compare the activity of selected muscles of trunk and lower extremities during walking among young women on supinated, pronated, and normal foot.

\section{Materials and methods}

\section{Participants}

This is a semi-experimental research included in comparative researches. Of girl students 18-25 years old, 45 were placed in three 15-member groups of normal, pronated and supinated foot. The people having orthopedic symptoms, skeletal-muscular injuries, chronic joint pain and any neurovascular and cardiac discover were excluded from the research. No subject had no experience of using medical shoes and used no walking aid. Before the experiment, all subjects filled consent form to participate in the study. The research was issued by Ethics Committee of Hamadan Medical Science University and the consent forms were confirmed by the committee.

\section{Foot measurement}

To determine the exact structure of foot, X-ray was used in full profile and semi profile of foot in bearing weight under knee. The final confirmation of foot structure was carried out with X-ray under orthopedic physician and Foot Posture Index (FPI). In the method of foot structure determination and abnormality severity of FPI, the subjects stood in a position where feet are parallel and open to shoulder width. The subjects were asked to divide their weight on the feet equally. Then, the researcher observes six indexes of interest from back view, as following: talar head palpation, supra and infra malleolar curvature, calcaneal frontal plane position, prominence in the region of the talonavicular joint, congruence of the medial longitudinal arch, and abduction/adduction of the forefoot on the rearfoot. After completion of assessing every six indexes and labeling them, the scores were added together. The score summed is placed at -12 (over supination) and 12 (over pronation) by experimenter. Those, whose FPI index is at $1-7$, are in normal foot group, those whose score is +8 to +10 at pronated foot group and those whose score is at +11 and 12 are at over pronated group. If the index is 0 to -3 , or -4 to -12 , the subject belongs to supinated foot group or over supinated group, respectively. ${ }^{26} \mathrm{FPI}$ measurements have shown good validity. ${ }^{27}$

\section{Instrument}

Superficial electromyography of muscles was made with a 16-channel device. One foot in each subject was analyzed. EMG signals were collected from tibialis anterior, peroneus longus, medial gastrocnemius, biceps femoris, gluteus medius, external oblique, erector spinae using a 16-channel system of MYON (model: MYON m320) in sampling frequency $1200 \mathrm{~Hz}$. Dipole electrodes (electrode type: H124SG-Covidien) containing glue and conducting jelly were used. The electrode size was $(24 \mathrm{~mm})$, and internal distance of electrodes $(20 \mathrm{~mm})$. Skin preparation (hair shaving, skin rob with alcoholic cotton) were based on SENIAM protocol. ${ }^{28}$ To determine the contact time of heel and midstance, six cameras (Vicon T40-S) were used at $120 \mathrm{~Hz}$. Markers were placed at the following places: 1st metatarsal head (left, right), 5th metatarsal head (left, right), heel (left, right) and head of foot thumb (left, right).

To analyze electromyography data during walking, the contact time of heel and ground and midstance had to be determined, with camera vertically. The least amount of camera data in the heel of right foot during walking was considered to be contact time of heel with ground and 
midstance when the left foot finger marker took off the ground and the person stood on the right foot.

The subjects were allowed to walk on a 10-m path for $2 \mathrm{~min}$ in their selected speed before the test. To prevent the speed effects on EMG parameters, the speed was controlled with a chronometer. In each path, the data were collected for $10 \mathrm{~s}$. To minimize the percentage of error, raw data were passed from band-pass filter $(10-450 \mathrm{~Hz}) .{ }^{29}$ In electromyography signal processing, to provide the comparison between different muscles and different subjects, maximal voluntary isometric contraction (MVIC) was carried out with Perotto protocol. For normalization, maximum surface electromyography signals were evaluated during each MVIC maneuver considered for $5 \mathrm{~s}$ for each muscle. ${ }^{30}$ The root mean square (RMS) during gait was normalized as a percentage of the MVIC (\%MVIC).

\section{Statistical method}

Mean and SD of data were used for descriptive statics. To determine normality of variable distribution, Kolmogorov-Smirnov and one-way ANOVA to compare groups in the information related to independent variables were used at significance level of 0.05. Tukey's post hoc test was used to determine significant differences between muscles.

\section{Results}

The subjects' characteristics are shown in Table 1. Subjects were similar in age, body mass index, height and weight in all groups, with no significant differences for any of these characteristics except for the foot posture index measure.

Comparisons of selected muscles activity between the normal, supinated and pronated foot groups during heel contact phase of walking are presented in Table 2. For tibialis anterior, the pronated foot group exhibited a greater muscle activity than that in normal and supinated foot groups $(p=0.001)$. There was similar behavior muscle activation for medial gastrocnemius as same as tibialis anterion (0.001). For peroneus longus, there was a significantly greater muscle activity in supinated foot group than that in normal and pronated groups $(p=0.001)$. No significant

\begin{tabular}{|c|c|c|c|}
\hline \multirow[t]{2}{*}{ Variable } & \multicolumn{3}{|c|}{ Groups } \\
\hline & Normal & Pronated & Supinated \\
\hline Age (years) & $22.1 \pm 1.9$ & $23.2 \pm 3.7$ & $22.2 \pm 2.8$ \\
\hline Height (cm) & $169.3 \pm 6.2$ & $165.6 \pm 5.2$ & $167.6 \pm 4.1$ \\
\hline Weight (kg) & $67.4 \pm 5.1$ & $68.4 \pm 4.9$ & $65.4 \pm 5.2$ \\
\hline $\mathrm{BMI}$ & $20.2 \pm 1.5$ & $21.8 \pm 1.9$ & $20.5 \pm 1.6$ \\
\hline $\mathrm{FPI}^{*}$ & $+4.1 \pm 1.7$ & $+9.6 \pm 1.1$ & $-2.3 \pm 1.4$ \\
\hline
\end{tabular}

Abbreviations: BMI, Body Mass Index; FPI, Foot Posture Index. The sign $\left({ }^{*}\right)$ shows the difference between pronated, supinated and normal foot groups.

differences were observed for remaining four muscles $(p>0.05)$.

Table 3 shows the means and standard deviations (SD) of the selected muscles activation during midstance phase of walking between all three groups of the study. One-way ANOVA followed by Tukey test indicated no significant differences between all groups of the study for tibialis anterior, biceps femoris, gluteus medius and erector spinae activation during midstance phase $(p>0.05)$. For peroneus longus, supinated foot group exhibited a greater electromyography activity in comparison with normal and pronated foot groups $(p=0.001)$. We observed a significant difference between normal and pronated foot groups for external oblique $(p=0.001)$. For gluteus medius, the pronated foot group exhibited a greater muscle activity than that in normal and supinated foot groups $(p=0.001)$.

\section{Discussion}

This study aimed to examine the effect of different foot types on electromyography activity of selected lower limb muscles during walking among young women. The results showed that the muscle activity of tibialis anterior in heel contact in pronated foot group was significantly greater than normal group but no significant difference in midstance phase in three groups. These findings corresponds with Murley and colleagues observations that the greater tibialis

Table 2 Mean \pm standard deviation of muscle activity involved in different foot postures at heel contact phase during walking (\%EMG $\mathrm{MVIC}_{\text {). }}$

\begin{tabular}{|c|c|c|c|c|c|}
\hline \multirow[t]{2}{*}{ Muscles } & \multicolumn{3}{|c|}{ Groups } & \multirow[t]{2}{*}{$P$-value } & \multirow[t]{2}{*}{$F$} \\
\hline & Normal & Pronated & Supinated & & \\
\hline Tibialis anterior & $3.35 \pm 10.89^{*}$ & $6.94 \pm 18.65^{\hbar^{*}}$ & $6.29 \pm 10.62^{\dagger}$ & 0.001 & 8.77 \\
\hline Peroneus longus & $1.49 \pm 5.20$ & $1.75 \pm 3.82^{\dagger}$ & $4.78 \pm 13.00^{\dagger}$ & 0.001 & 39.04 \\
\hline Medial gastrocnemius & $0.79 \pm 3.99^{*}$ & $1.75 \pm 6.51^{\dagger^{*}}$ & $1.73 \pm 4.71^{\dagger}$ & 0.001 & 11.31 \\
\hline Biceps femoris & $1.80 \pm 7.84$ & $3.53 \pm 9.24$ & $2.20 \pm 7.44$ & 0.155 & 1.95 \\
\hline Gluteus medius & $1.89 \pm 6.28$ & $3.58 \pm 7.70$ & $2.37 \pm 8.48$ & 0.091 & 2.54 \\
\hline External oblique & $2.92 \pm 6.41$ & $3.66 \pm 7.52$ & $4.48 \pm 8.36$ & 0.666 & 1.02 \\
\hline Erector spinae & $2.21 \pm 8.83$ & $3.87 \pm 7.29$ & $3.98 \pm 9.62$ & 0.183 & 1.76 \\
\hline
\end{tabular}

Abbreviations: $P$-value stands for probability value; $F$ stands for $F$-statistic.

" Significance level for normal and pronated foot group, significance level for normal and supinated foot group.

Significance level for pronated and supinated group $(p<0.05)$. 
Table 3 Mean \pm standard deviation of muscle activity involved in different foot postures at midstance phase during walking $\left(\% \mathrm{EMG}_{M V I C}\right)$.

\begin{tabular}{|c|c|c|c|c|c|}
\hline \multirow[t]{2}{*}{ Muscles } & \multicolumn{3}{|c|}{ Groups } & \multirow[t]{2}{*}{$P$-value } & \multirow[t]{2}{*}{$F$} \\
\hline & Normal & Pronated & Supinated & & \\
\hline Tibialis anterior & $1.13 \pm 4.12$ & $3.81 \pm 6.34$ & $3.18 \pm 6.05$ & 0.114 & 2.288 \\
\hline Peroneus longus & $1.37 \pm 5.12$ & $1.43 \pm 3.24^{\dagger}$ & $2.43 \pm 15.54$ & 0.001 & 187.98 \\
\hline Medial gastrocnemius & $2.72 \pm 8.34^{*}$ & $3.61 \pm 11.93^{* \dagger}$ & $1.61 \pm 7.33^{\dagger}$ & 0.001 & 11.355 \\
\hline Biceps femoris & $2.30 \pm 5.64$ & $1.45 \pm 6.55$ & $0.96 \pm 5.82$ & 0.297 & 1.249 \\
\hline Gluteus medius & $1.51 \pm 7.43$ & $1.34 \pm 7.96$ & $1.47 \pm 8.71$ & 0.061 & 2.993 \\
\hline External oblique & $6.25 \pm 9.82^{*}$ & $2.18 \pm 14.54^{*}$ & $5.20 \pm 10.43$ & 0.022 & 4.162 \\
\hline Erector spinae & $2.21 \pm 5.75$ & $2.51 \pm 6.78$ & $2.26 \pm 4.74$ & 0.068 & 2.86 \\
\hline
\end{tabular}

Abbreviations: $P$-value stands for probability value; $F$ stands for $F$-statistic.

Significance level for normal and pronated foot group, significance level for normal and supinated foot group.

$\dagger$ Significance level for pronated and supinated group $(p<0.05)$.

anterior activation in the pronated foot group during this same phase of gait. ${ }^{4}$ They attributed this finding in pronated foot to the possibility that tibialis anterior in heel contact phase has greater activity to control plantar flextion and decelerate ankle joint plantar flexion and resist foot pronation. In other words, tibialis anterior increases its activity and continues action in order to sustain rearfoot inversion to distribute the weight on the lateral border of the foot rather than the medial border. Moreover, it reported that supinated foot is associated with peroneus brevis and tibialis anterior tendon weakness and tibialis posterior overpowering, ${ }^{15}$ thus may leads to compensatory mechanism and changes in activity level of tibialis anterior.

The results of this research for muscle activity of peroneus longus showed that in the pronated foot group, it was significantly less than that in normal and supinated foot group in the contact of heel with ground and midstance during walking. These findings show that the muscle of peroneus longus in the pronated foot group had less activity in contact of heel and midstance than normal and supinated foot group. These performance differences between feet are likely to show less activity of peroneus longus muscle in the pronated foot to make a compensatory mechanism to prevent from greater pressure on internal arch. ${ }^{4}$ Also, the greater activity of peroneus longus muscle in supinated foot group than pronated foot group occurs in reaction to supination in subtalar joint in this group.

For biceps femoris, gluteus medius and erector spinae muscles, there was no significant difference among three groups. These show that the muscle activity of biceps femoris, external oblique and erector spinae are not influenced by foot structure in contact of heel and ground and midstance phases of gait. As change in the structure of rearfoot did not make any change in the activity of this muscle it seems unlikely that these muscles play important roles in invertor or evertor of foot in pronated and supinated foot groups compared with normal foot groups. To the best of our knowledge, no direct study has evaluated the effects of foot type on above mentioned muscles. But some studies show weakness of the gluteus medius as a hip abductor can be the cause of some injuries that are attributed to excessive subtalar pronation. During the heel strike while running or walking, the gluteus medius must contract to maintain good position of the hip, femur, knee, tibia, and foot. If there is a weakness in the gluteal muscles, the hip will adduct, causing the femur, knee, and tibia to rotate inwards. This excessive inward rotation of the leg causes an increase in pronation at the foot. The muscles in the foot that control pronation are not strong enough to counteract these forces from the hip and lower leg. The result is excessive pronation and potential injuries. It is shown that women have greater hip adduction during sporting maneuvers, which leads to a higher knee abduction and greater loading on the ACL. For instance, previous study that showed difference between sexes in gluteus medius activity was conducted by Hart and colleagues. They examine 8 male and 8 female division-one soccer athletes performed a single-leg forward jump. Surface EMG was collected for the gluteus medius, along with hamstrings, quadriceps, and gastrocnemius muscles, where results showed that the average gluteus medius activity was significantly higher in males compared to females. There was no significant difference between sexes for any other muscles collected. ${ }^{31}$ Possibly, this existing gender difference showed no significant gluteus medius activation during walking among the groups with different foot types in our study.

The increase of muscle activity of medial gastrocnemius during walking has been reported as a compensatory mechanism related to mechanical disturbances of joint. ${ }^{32}$ Medial gastrocnemius leads to plantar flexor and invertor momentum of ankle and prevents from extra pronation of ankle as a dynamic fixer. ${ }^{33}$ When the subtalar joint has over evertion, the performance of medial gastrocnemius increases. ${ }^{34}$

The electromyography activity of external oblique muscle in pronated foot in midstance was greater than that in normal foot group. Due to lack of research comparing the external oblique muscle for individuals with different foot structures, we were not able to get a comparison. As pronated foot is a combination of rearfoot valgus and forefoot varus, thus pronation in subtalar joint results in anterior pelvic tilt instance, producing more pressure and stress while disturbing the ability of muscles responsible for pelvic stability and increasing pathologic pressures on supporting tissues of sacroiliac joint. As external oblique muscle is the greatest abdominal muscle controlling the rotation to front of pelvis, in the case of stability in spine, the activity of external muscle activity increases; therefore, 
to compensate this deficiency, this postural muscle is forced to have more activity to compensate imbalance. ${ }^{35}$ In addition, the strength point of this study was to consider the possible role the truck muscles as well as lower limb muscles in females with normal, pronated and supinated during gait. As mentioned earlier evidences show that women have greater hip adduction during sporting maneuvers, which leads to the knee injuries. Furthermore, it is documented that foot deformities may alter the mechanical alignment and dynamic function in proximal joint consequently, affect the gait pattern. So, there was need to examine the effect of gluteal and trunk muscles during gait. Our findings revealed that the gluteal and trunk muscles of the women with different foot types who participated in our study did not significantly changed during stance and heel contact phases of gait. According to these findings, lower limb muscle function is affected by foot type, therefore we suggest rehabilitation exercise programs for improving lower limb muscle strength related to foot deformities. The limitation of this study was that invertor activity of tibialis posterior was not determined due to the needle electromyography record. The results of this research can help the rehabilitation experts to design exercise programs for people having abnormal structure.

\section{Conclusion}

As pronation and supination bring about changes in lower extremities and pelvic-back area, they make change in performance of some selected muscles in pronated and supinated foot group compared with normal foot group. The performance of muscles is under the foot structure. This difference in muscle activity can act as a neuromuscular compensatory mechanism to reduce the overweight internal longitudinal arch in pronated foot individuals.

\section{Conflict of interest}

Authors declare that they do not have any conflict of interests.

\section{References}

1. Barwick A, Smith J, Chuter V. The relationship between foot motion and lumbopelvic-hip function: a review of the literature. Foot. 2012;22:224-31.

2. Lundgren P, Nester C, Liu A, Arndt A, Jones R, Stacoff A, et al. Invasive in vivo measurement of rear-, mid- and forefoot motion during walking. Gait Posture. 2008;28:93-100.

3. Massie D, Haddox A. Influence of lower extremity biomechanics and muscle imbalances on the lumbar spine. Athl Ther Today. 1999;3:46-51.

4. Murley GS, Menz HB, Landorf KB. Foot posture influences the electromyographic activity of selected lower limb muscles during gait. J Foot Ankle Res. 2009;2:35.

5. Burns J, Keenan AM, Redmond A. Foot type and overuse injury in triathletes. J Am Podiatr Med Assoc. 2005;95:235-41.

6. Manoli A, Graham B. The subtle cavus foot: the underpronator a review. Foot Ankle Int. 2005;26:256-63.

7. Williams DS, Davis IM, Scholz JP, Hamill J, Buchanan TS. Higharched runner's exhibit increased leg stiffness compared to lowarched runners. Gait Posture. 2004;19:263-9.
8. Pinto RZ, Souza TR, Trede RG, Kirkwood RN, Figueiredo EM, Fonseca ST. Bilateral and unilateral increases in calcaneal eversion affect pelvic alignment in standing position. Man Ther. 2008;13:513-9.

9. Willson JD, Dougherty CP, Ireland ML, McClay D. Core stability and its relationship to lower extremity function. J Am Acad Orthop Surg. 2005;13:316-25.

10. Tiberio D. Effect of excessive subtalar joint pronation on patellofemoral mechanics: a theoretical model. J Orthop Sports Phys Ther. 1987;9:160-5.

11. Tiberio D. Pathomechanics of structural foot deformities. J Phys Ther. 1988;68:1840-9.

12. Dierks TA, Manal KT, Hamill J, Davis IS. Proximal and distal influences on hip and knee kinematics in runners with patellofemoral pain during a prolonged run. J Orthop Sports Phys Ther. 2008;38:448-56.

13. Bird AR, Payne CB. Foot function and low back pain. Foot. 1999;9:175-80.

14. Theodoros N, Dimitris M, Efstathios C, Spyros A. EMG activation of trunk and upper limb muscles following experimentallyinduced overpronation and oversupination of the feet in quiet standing. Gait Posture. 2013:190-4.

15. Hansen ST. The cavovarus/supinated foot deformity and external tibia torsion: the role of the posterior tibia tendon. Foot Ankle Clin. 2008;13:325-8.

16. Hunt AE, Smith RM. Mechanics and control of the flat versus normal foot during the stance phase of walking. Clin Biomech. 2004; 19:391-7.

17. Razeghi M, Batt ME. Foot type classification: a critical review of current methods. Gait Posture. 2004;15:282-91.

18. Dorsey S, Williams IS, McClay JH, Thomas S. Buchanan lower extremity kinematic and kinetic differences in runners with high and low arches. J Appl Biomech. 2001;17:153-63.

19. Keenan MA, Peabody TD, Gronley JK, Perry J. Valgus deformities of the feet and characteristics of gait in patients who have rheumatoid arthritis. J Bone Joint Surg Am. 1991;73: 237-47.

20. Perry J. Gait analysis: normal and pathological function. New Jersey: Thorofare, SLACK Inc.; 1992. p. 136-7.

21. Smeathers J. Shocking news about discs. Curr Orthop. 1994;8: $45-8$.

22. Vleeming A, Pool-Goudzwaard AL, Stoeckart R, Van Wingerden JP, Snijders CJ. The posterior layer of the thoracolumbar fascia. Its function in load transfer from spine to legs. Spine. 1995;1: 753-8.

23. Stecco A, Macchi V, Masiero S, Porzionato A, Tiengo C, Stecco C. Pectoral and femoral fasciae: common aspects and regional specializations. Surg Radiol Anat. 2009;31:35-42.

24. Myers TW. Anatomy trains. Myofascial meridians for manual and movement therapists. London: Churchill Livingstone; 2001.

25. Janda V. Muscle function testing. London: Butterworths; 1983.

26. Redmond AC, Crosbie J, Ouvrier AR. Development and validation of a novel rating system for scoring standing foot posture: the foot posture index. Clin Biomech. 2006;21:89-98.

27. Evans Angela M, Rome K, Peet L. The foot posture index, ankle lunge test, Beighton scale and the lower limb assessment score in healthy children: a reliability study. J Foot Ankle Res. 2012;5:1.

28. Hermens DH, Feriks B. Surface electromyography for the noninvasive assessment of muscle (SENIAM); 2005.

29. De Luca CJ, Donald Gilmore L, Mikhail K, Serge HR. Filtering the surface EMG signal: movement artifact and baseline noise contamination. J Biomech. 2010;43:1573-9.

30. Perotto AO, Delagi EF, Lazzetti J, Morrison D. Anatomical guide for the electromyographer: the limbs and trunks. 3rd ed. Springfield, IL: Charls C. Thomas; 1994.

31. Hart JM, Garrison JC, Kerrigan DC, Palmieri-Smith R, Ingersoll $\mathrm{CD}$. Gender differences in gluteus medius muscle activity exist 
in soccer players performing a forward jump. Res Sports Med. 2007;15:147-55.

32. Ringleb SI, Kavros SJ, Kotajarvi BR, Hansen DK, Kitaoka HB, Kaufman KR. Changes in gait associated with acute stage II posterior tibial tendon dysfunction. Gait Posture. 2007;25:555-64.

33. Simon SR, Mann RA, Hagy JL, Larsen LJ. Role of the posterior calf muscles in normal gait. J Bone Joint Surg Am. 1978;60:465-72.
34. Wang R, Gutierrez-Farewik EM. The effect of subtalar inversion/eversion on the dynamic function of the tibialis anterior, soleus, and gastrocnemius during the stance phase of gait. Gait Posture. 2011;34:29-35.

35. Dinsdale N. How abnormal foot motion can be a major contributor to lower back and pelvic problems. SportEX Dyn. 2009;19:11-4. 